\title{
РАЗРАБОТКА РЕЦЕПТУРЫ И ТЕХНОЛОГИИ МЯСНОГО РУБЛЕНОГО ПОЛУФАБРИКАТА С РАСТИТЕЛЬНЫМ КОМПОНЕНТОМ
}

\author{
N.A. Velichko, A.A. Pyanzina
}

\section{THE DEVELOPMENT OF THE RECIPE AND THE TECHNOLOGY OF CHOPPED MEAT SEMI-FINISHED PRODUCT WITH VEGETABLE COMPONENT}

Величко Надежда Александровна - д-р техн. наук, проф., зав. каф. технологии консервирования и пищевой биотехнологии Красноярского государственного аграрного университета, г. Красноярск.

E-mail: vena@kgau.ru

Пьянзина Анна Анатольевна - магистрант каф. технологии консервирования и пищевой биотехнологии Красноярского государственного аграрного университета, г. Красноярск.

E-mail: vena@kgau.ru

Цель исследования - разработка новой реuептуры колбасок для жарки «Командорыч» с добавлением растительного компонента фрасолевой муки, соответствующих по качественным показателям требованиям нормативной документации. Объектом исследования были колбаски для жарки, приготовленные по традиционной технологии (контрольный образеи), и колбаски для жарки с введением компонента растительного происхождения фасолевой муки (опьтный образеи). Предметом исследования являлась разработка реuептур и технологии мясных рубленых полуфабрикатов с добавлением растительного сырья - фасолевой муки, а также оценка качества полученных продуктов. Экспериментальные исследования были проведены на кафедре технологии консервирования и пищевой биотехнологии Института пищевых производств и предприятии ИП Черномуров А.М., столовая «Аллея» (е. Красноярск). Разработана рещептура мясного рубленого полусабриката - колбасок для жарки с фрасолевой мукой. $B$ мясной фрарш вносилась гидратированная фрасолевая мука в различных дозировках - 10; 15; 20 \%. Подобрана дозировка растительного компонента (15\% фрасолевой муки взамен мясного фрарша), при которой установлены наи-
Velichko Nadezhda Alexandrovna - Dr. Techn. Sci., Prof., Head, Chair of Technology of Canning and Food Biotechnology, Krasnoyarsk State Agrarian University, Krasnoyarsk.

E-mail: vena@kgau.ru

Pyanzina Anna Anatolyevna - Magistrate Student, Chair of Technology of Canning and Food Biotechnology, Krasnoyarsk State Agrarian University, Krasnoyarsk.

E-mail: vena@kgau.ru

лучшие органолептические показатели продукта: внешний вид и вкус соответствовали данному виду продукта, ивет был розоватосерый, запах приятный, консистенция - как у контрольного образца. Предложена принципиальная схема получения колбасок для жарки с фрасолевой мукой, которая вносится на стадии приготовления фрарша в гидратированном состоянии в соотношении 1 : 3. Определены физико-химические, органолептические и микробиологические показатели колбасок для жарки. Показано их соответствие нормативной документации ГОСТ P 9959-2015 и TP TC 021/2011.

Ключевые слова: колбаски для жарки, рецептура, дозировка, фрасолевая мука, показатели качества, принципиальная схема.

The research objective was the development of a new recipe of "Komandorych", the sausages for frying with addition of vegetable component - bean flour, conforming in the quality indicators to the requirements of standard documentation. The sausages for frying prepared on traditional technology (a control sample) and the sausages for frying with introduction of the component of phytogenesis bean flour (prototype) were the object of the research. The subject of the research was the devel- 
opment of recipes and technology of meat chopped semi-finished products with addition of vegetable raw materials - bean flour, and also the assessment of the quality of received products. Pilot studies were conducted on the Chair of Technology of Conservation and Food Biotechnology of Institute of Food Productions and the SP Enterprise Chernomurov A.M., canteen "Alleya" (Krasnoyarsk). The recipe of meat chopped semi-finished product - sausages was developed for frying with bean flour. Hydrated bean flour in various dosages 10 was added into the mincemeat; $15 ; 20 \%$. The dosage of vegetable component (15\% of bean flour instead of mincemeat) was picked up at which the best organoleptic indicators of the product were established: the appearance and taste corresponded to this type of the product; the color was pinkishgray, with pleasant smell, the consistence was as in the control sample. Schematic diagram of receiving sausages for frying with bean flour which brought at the stage of preparation of minced meat in hydrated state in the ratio $1: 3$ was offered. Physical and chemical, organoleptic and microbiological indicators of sausages for frying were defined. Their compliance to standard documentation of State Standard P 9959-2015 and TR TC 021/2011 was shown.

Keywords: sausages for frying, recipe, dosage, bean flour, quality indicators, schematic diagram.

Введение. Практически в пищевом рационе каждого человека присутствуют мясные рубленые полуфабрикаты, и их доля потребления ежегодно увеличивается. Большое значение мясные полусрабрикаты имеют для предприятий общественного питания, облегчают и уменьшают работу заготовочных цехов, сокращают продолжительность процесса приготовления мясного изделия, повышают производительность предприятия, ассортимент, обеспечивая сохранение всех вкусовых и полезных свойств продукта [1].

Рубленые полуфабрикаты обладают высокой пищевой ценностью, усвояемостью и вкусовыми достоинствами. Ежегодно происходит увеличение их ассортимента за счет включения в рецептуру различных растительных и вкусовых компонентов, таких как овощи, крупы, мука, соевые добавки, специи, приправы и другие белковые ингредиенты.
Исследование возможности новых растительных ингредиентов (фасолевой муки) в рецептурах мясных рубленых полуфрабрикатов представляет несомненный интерес в связи с тем, что воздействие фасолевой муки на организм человека проявляется в улучшении пищеварительных процессов и функций кровеносной системы, благодаря высокому содержанию пищевых волокон, биологически активных и минеральных веществ [2-4].

Включение фасолевой муки в рацион питания человека способствует повышению общего самочувствия, стимуляции обмена веществ, очищению организма от шлаков и повышению его иммунных способностей. Отсутствие быстроусвояемых углеводов, низкий гликемический индекс также делает эту муку отлично подходящей для диетического питания.

Калорийность 100 г муки составляет 440 кКал $[2,3]$.

Цель исследования: разработка новой рецептуры колбасок для жарки «Командорыч» с добавлением растительного компонента - фасолевой муки, соответствующей по качественным показателям требованиям нормативной документации.

\section{Задачи исследования:}

- разработать рецептуру мясного рубленого полуфабриката с растительным компонентом фасолевой мукой;

- определить дозировку фасолевой муки в рецептуре колбасок для жарки, при которой продукт приобретает наилучшие органолептические показатели;

- установить показатели качества разработанного продукта;

- разработать принципиальную схему получения колбасок для жарки с растительным компонентом - фасолевой мукой.

Методы и материалы исследования. Экспериментальные исследования были проведены на кафедре технологии консервирования и пищевой биотехнологии Института пищевых производств Красноярского ГАУ и предприятии ИП Черномуров А.М., столовая «Аллея», г. Красноярск.

Предметом исследования являлась разработка рецептур и технологии полуфабрикатов с добавлением растительного сырья, а также оценка качества полученных продуктов. 
Объектом исследования были колбаски для жарки, приготовленные по традиционной технологии (контрольный образец) и колбаски для жарки с введением компонента растительного происхождения - фасолевой муки (опытный образец).

При разработке рецептур использовали следующее сырье:

- говядина - по ГОСТ 32606-2013;

- свинина - по ГОСТ Р 52986-2008;

- чеснок - по ГОСТ 33562-2015;

- мука фрасолевая - по ГОСТ 7758-1975;

- лук репчатый свежий - по ГОСТ 1723-2015;

- перец черный молотый - по ГОСТ 29050-91;

- соль поваренная - по ГОСТ Р 51574-2018.

Сырье, применяемое для приготовления колбасок, соответствует требованиям технической документации и ТP ТС 021/2011 «О безопасности пищевой продукции» [5].

Органолептические показатели в готовом изделии исследовались в соответствии с ГОСТ
9959-2015 «Продукты мясные. Общие условия проведения органолептической оценки» [6].

По ГОСТ Р 51447-99 «Мясо и мясные продукты. Методы отбора проб» проводили отбор средних проб готового продукта [5]. Определение влаги проводили по ГОСТ Р 51749-1999 «Мясо и мясные продукты. Метод определения массовой доли влаги» [7].

Результаты исследования и их обсуждение. В мясные фрарши вносили фрасолевую муку на основании предварительно проведенных экспериментов в количестве 10; 15; 20 \% взамен мясного сырья. Разработанные рецептуры колбасок для жарки с добавлением различных дозировок фасолевой муки приведены в таблице 1.

Для определения органолептических показателей колбасок для жарки был использован метод органолептического анализа, полученные результаты приведены в таблице 2.

Таблица 1

Рецептура колбасок для жарки контрольный и опытный образцы на 100 г продукта

\begin{tabular}{|l|c|c|c|c|}
\hline \multirow{2}{*}{\multicolumn{1}{|c|}{ Сырье, г }} & \multirow{2}{*}{$\begin{array}{c}\text { Контрольный } \\
\text { образец }\end{array}$} & \multicolumn{3}{c|}{ Опытные образцы } \\
\cline { 3 - 5 } & 47,2 & $10 \%$ & $15 \%$ & $20 \%$ \\
\hline Говядина & 35,2 & 33,2 & 41,2 & 39,2 \\
\hline Свинина & - & 8,24 & 12,36 & 16,48 \\
\hline $\begin{array}{l}\text { Гидратированная } \\
\text { фасолевая мука }\end{array}$ & & 3,4 & 3,4 & 3,4 \\
\hline Чеснок & 3,4 & 8,2 & 8,2 & 8,2 \\
\hline Лук & 8,2 & 3,6 & 3,6 & 3,6 \\
\hline Специи & 3,6 & 2,4 & 2,4 & 2,4 \\
\hline Черева & 2,4 & 100 & 100 & 100 \\
\hline Масса нетто & 100 & & & \\
\hline
\end{tabular}

Согласно полученным результатам было установлено, что дозировка введения фасолевой муки в колбаски для жарки в количестве 15 \% от общей массы фарша обеспечивает высокие органолептические показатели, а именно: внешний вид и вкус соответствовали данному виду продукта, цвет был розовато-серый, запах приятный, консистенция была как у контрольного образца. Разработанный полуфрабрикат по органолептическим показателям соответствует требованиям ГОСТ 9959-2015.

Содержание влаги в продукте составило 52 \%, что соответствует нормативной документации.
Одним из физико-химических показателей, определяющих качество колбасок для жарки, является показатель влагосвязывающей способности, который составил 92,25 \%. Жироудерживающая способность (ЖУС) колбасок для жарки с добавлением фасолевой муки $15 \%$ ниже на 2,43 \% по сравнению с контрольным образцом, влагоудерживающая способность как контрольного, так и опытного образцов сопоставимы $(50 \%)$.

Результаты микробиологических исследований контрольного и опытных образцов представлены в таблице 3. 
Органолептический анализ контрольного и опытных образцов

\begin{tabular}{|c|c|c|c|c|}
\hline Продукт & Внешний вид & Цвет & Вкус и запах & Консистенция \\
\hline $\begin{array}{l}\text { Контрольный } \\
\text { образец }\end{array}$ & $\begin{array}{c}\text { Однородная мелкоизмель- } \\
\text { ченная масса с незначи- } \\
\text { тельным количеством вы- } \\
\text { плавленного жира }\end{array}$ & $\begin{array}{l}\text { Розовато- } \\
\text { серый }\end{array}$ & $\begin{array}{c}\text { Свойственный колба- } \\
\text { скам для жарки } \\
\text { с ароматом пряностей, } \\
\text { без постороннего запа- } \\
\text { ха и привкуса }\end{array}$ & Однородная \\
\hline $\begin{array}{l}\text { Опытный } \\
\text { образец } 1 \text { (10 \%) }\end{array}$ & $\begin{array}{c}\text { Соответствует данному } \\
\text { виду продукта }\end{array}$ & $\begin{array}{l}\text { Розовато- } \\
\text { серый }\end{array}$ & $\begin{array}{c}\text { Свойственный колба- } \\
\text { скам для жарки } \\
\text { с ароматом пряностей, } \\
\text { без постороннего запа- } \\
\text { ха и привкуса }\end{array}$ & Однородная \\
\hline $\begin{array}{l}\text { Опытный } \\
\text { образец } 2 \text { (15 \%) }\end{array}$ & $\begin{array}{c}\text { Соответствует данному } \\
\text { виду продукта }\end{array}$ & $\begin{array}{l}\text { Розовато- } \\
\text { серый }\end{array}$ & $\begin{array}{c}\text { Свойственный колба- } \\
\text { скам для жарки } \\
\text { с ароматом пряностей, } \\
\text { без постороннего запа- } \\
\text { ха, с послевкусием фра- } \\
\text { солевой муки }\end{array}$ & Однородная \\
\hline $\begin{array}{l}\text { Опытный } \\
\text { образец } 3 \text { (20 \%) }\end{array}$ & $\begin{array}{c}\text { Соответствует данному } \\
\text { виду продукта }\end{array}$ & $\begin{array}{l}\text { Розовато- } \\
\text { серый }\end{array}$ & $\begin{array}{c}\text { Свойственный колба- } \\
\text { скам для жарки } \\
\text { с ароматом пряностей, } \\
\text { без постороннего запа- } \\
\text { ха, с привкусом фрасо- } \\
\text { левой муки. Не доста- } \\
\text { точно сочности }\end{array}$ & Однородная \\
\hline
\end{tabular}

Микробиологические показатели контрольного и опытного образцов

\begin{tabular}{|l|c|c|}
\hline \multicolumn{1}{|c|}{ Показатель } & $\begin{array}{c}\text { Колбаски для жарки } \\
\text { (контрольный образец) }\end{array}$ & $\begin{array}{c}\text { Колбаски для жарки с добавлением } \\
\text { фасолевой муки 15 \% }\end{array}$ \\
\hline КМАФАнМ & - & Не обнаружены \\
\hline БГКП & Не обнаружены & Не обнаружены \\
\hline $\begin{array}{l}\text { Сульфидредуцирующие } \\
\text { клостридии }\end{array}$ & Не обнаружены & Не обнаружены \\
\hline St.аureus & Не обнаружены & Не обнаружены \\
\hline $\begin{array}{l}\text { Патогенные микробы, } \\
\text { в т. ч. сальмонеллы }\end{array}$ & Не обнаружены & \multicolumn{2}{|c|}{} \\
\hline
\end{tabular}

Результаты исследования показали, что микробиологические показатели соответствуют нормам ТР ТС 034/2013 «О безопасности мяса и мясной продукции» (табл. 3).
Принципиальная схема получения колбасок для жарки с фасолевой мукой приведена на рисунке. 


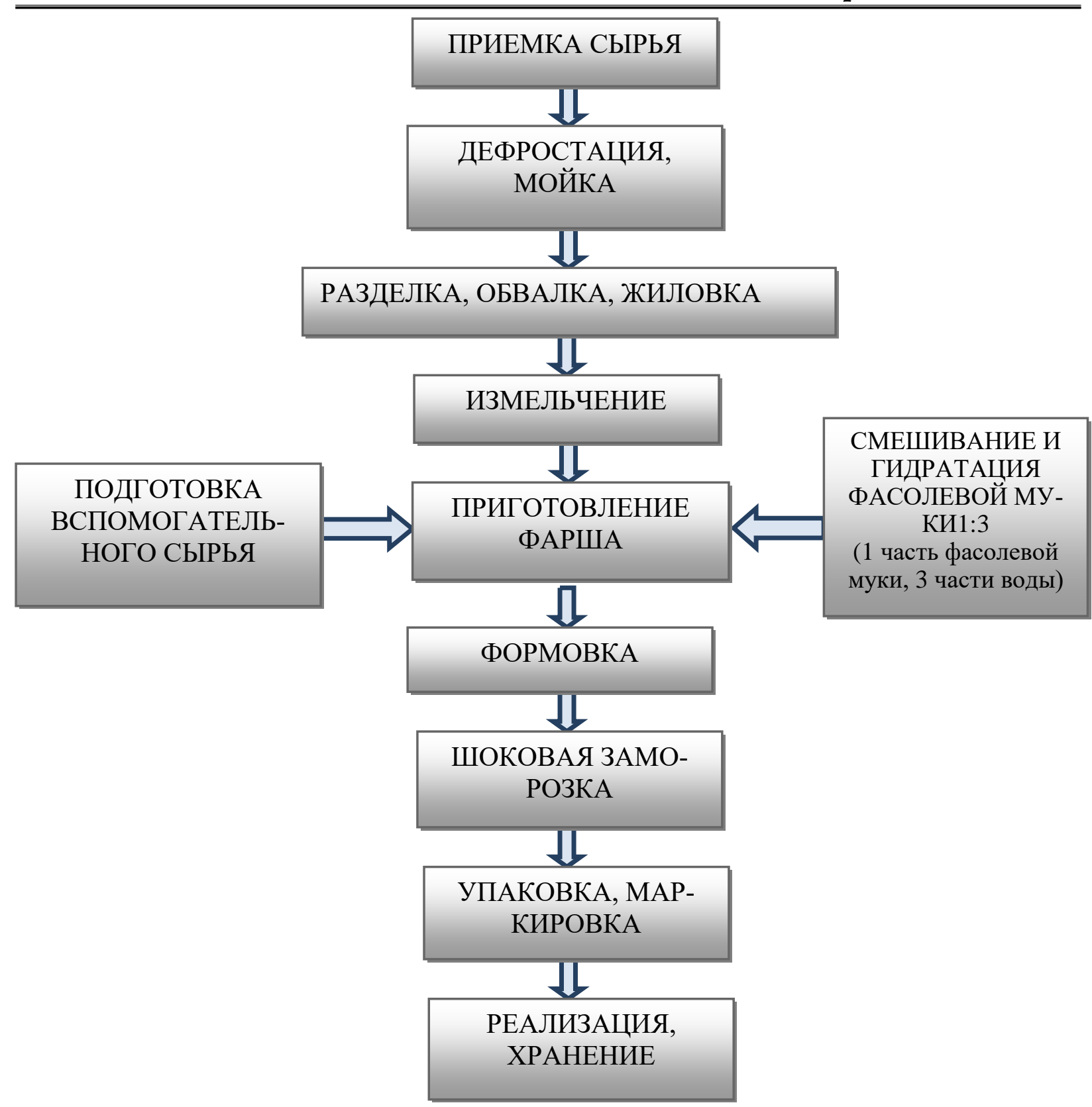

Принципиальная схема получения колбасок для жарки с фрасолевой мукой

Приемку сырья производят по сопроводительным документам: сертификатам или декларациям соответствия, ветеринарным свидетельствам, товаросопроводительным документам. Взвешивание производят на весах напольных с ценой деления 0,05 кг или напольных электронных, на весах настольных электронных или аналогичных устройствах.

Подготовка сырья проводится в соответствии с «Инструкцией по предупреждению попадания посторонних предметов в продукцию на пред- приятиях пищевой промышленности и в кооперативах».

Мясное сырье разделывают в соответствии с правилами разделки говядины, свинины, баранины, телятины, конины, оленины на предприятиях мясоперерабатывающей промышленности.

Фасолевую муку подвергают металлоулавливанию, гидратируют холодной водой в течение 15-20 мин. 
Лук репчатый, чеснок сортируют, очищают, промывают в проточной воде, удаляют донце и шейку, ополаскивают в проточной воде.

Соль поваренную, перец черный молотый просеивают сквозь сита с диаметром ячеек не более 2 мм, подвергают металлоулавливанию.

Мясо размораживают в специальных камерах медленным или быстрым способом.

Перед обмыванием с туш срезают загрязненные места, кровяные сгустки, ветеринарные клейма. Мытье мясных туш проводят в специально выделенном помещении. После обсушки туши подают на разделку.

Полученные при разделке части подвергают обвалке, т. е. отделению мякоти от костей. Обвалка производится в соответствии с действующими технологическими инструкциями, применяемыми в колбасном и полуфабрикатном производствах.

Приготовление фрарша. Мясное сырье измельчают на волчке и загружают в фраршемешалку или куттер, затем добавляют гидратированные волокна (фасолевая мука), соль, специи, измельченный лук, чеснок и воду. Тщательно перемешивают. Температура готового фарша не должна превышать $14^{\circ} \mathrm{C}$.

Изготовление полусфабриката. Для изготовления колбасок для жарки фарш пропускают через шприц-дозатор, формируя колбаски длиной 15-20 cм.

Готовые полуфабрикаты фасуют и направляют на охлаждение или замораживание в специальные камеры.

\section{Выводы}

1. Разработана рецептура колбасок для жарки с заменой части мясного фарша на фасолевую муку. Определена дозировка растительного компонента (15\%), при которой установлены наилучшие органолептические показатели продукта. При испытании новой продукции по органолептическим показателям выявлено соответствие ГОСТ Р 9959-2015 и ТР ТС 021/2011.

2. Определены физико-химические показатели колбасок для жарки с фасолевой мукой, которые соответствуют нормативной документации ТР ТС 021/2011.

3. Предложена принципиальная схема получения колбасок для жарки с добавлением фасолевой муки, которая вносится на стадии приготовления фрарша в гидратированном состоянии в соотношении $1: 3$.

\section{Литература}

1. Речкина Е.А., Губаненко Г.А., Машанов А.И. Анализ рынка мясных полусрабрикатов, представленных в торговых сетях г. Красноярска // Вестник КрасГАУ. 2015. № 4. С. 202-210.

2. Величко Н.А., Шароглазова Л.П., Рыгалова $E . A$. Влияние вида клетчатки на потребительские свойства колбасок для жарки // Мясной ряд. 2019. № 4-78. С. 58-59.

3. Скурихин И.М., Волгарева М.Н. Химический состав пищевых продуктов. Кн. 1. Справ. табл. содержания основных пищевых веществ и энергетической ценности пищевых продуктов. М.: Агропромиздат, 1987. 224 с.

4. Скурихин И.М., Волгарева М.Н. Химический состав пищевых продуктов. Кн. 2. Справ. табл. содержания аминокислот, жирных кислот, витаминов, макро- и микроэлементов, органических кислот и углеводов. М.: Агропромиздат, 1987. $360 \mathrm{c}$.

5. ТP ТС № 21/2011. О безопасности пищевой продукции. Введ. 2011-12-09. М.: Изд-во стандартов, 2011. $113 \mathrm{C}$.

6. ГОСТ 9959-2015. Продукты мясные. Общие условия органолептической оценки. Введ. 1993-01-01. М.: Стандартинформ, 2010. 12 с.

7. ГОСТ Р 51749-1999. Мясо и мясные продукты. Метод определения массовой доли влаги. Введ. 1999-12-22. М.: Стандартинформ, 2010. 8 с.

\section{Literatura}

1. Rechkina E.A., Gubanenko G.A., Mashanov A.I. Analiz rynka mjasnyh polufabrikatov, predstavlennyh $v$ torgovyh setjah g. Kras-nojarska // Vestnik KrasGAU. 2015. № 4. S. 202-210.

2. Velichko N.A., Sharoglazova L.P., Rygalova E.A. Vlijanie vida kletchatki na potrebitel'skie svojstva kolbasok dlja zharki // Mjasnoj rjad. 2019. № 4-78. S. 58-59. 
3. Skurihin I.M., Volgareva M.N. Himicheskij sostav pishhevyh produktov. Kn. 1. Sprav. tabl. soderzhanija osnovnyh pishhevyh veshhestv i jenergeticheskoj cennosti pishhevyh produktov. M.: Agropromizdat, 1987. $224 \mathrm{~s}$.

4. Skurihin I.M., Volgareva M.N. Himicheskij sostav pishhevyh produktov. Kn. 2. Sprav. tabl. soderzhanija aminokislot, zhirnyh kislot, vitaminov, makro- i mikrojelementov, organicheskih kislot $\mathrm{i}$ uglevodov. M.: Agropromizdat, 1987. $360 \mathrm{~s}$.
5. TR TS № 21/2011. O bezopasnosti pishhevoj produkcii. Vved. 2011-12-09. M.: Izd-vo standartov, 2011. $113 \mathrm{~s}$.

6. GOST 9959-2015. Produkty mjasnye. Obshhie uslovija organolepticheskoj ocenki. Vved. 1993-0101. M.: Standartinform, 2010. $12 \mathrm{~s}$.

7. GOST R 51749-1999. Mjaso i mjasnye produkty. Metod opredelenija massovoj doli vlagi. Vved. 1999-12-22. M.: Standartinform, 2010. 8 s. 